\title{
Risk for ischemic stroke and coronary heart disease associated with migraine and migraine medication among older adults
}

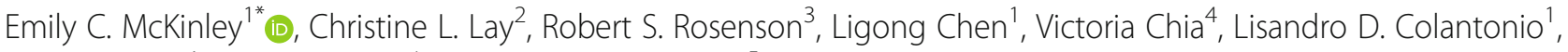
Paul Muntner ${ }^{1}$, Robert Urman ${ }^{4}$ and Michael E. Farkouh ${ }^{5}$

\begin{abstract}
Background: Migraine has been associated with cardiovascular disease (CVD) events among middle-aged adults. The objective of this study was to determine the risk for ischemic stroke and coronary heart disease (CHD) events among older adults with versus without migraine.
\end{abstract}

Methods: This retrospective cohort study was conducted using data from US adults $\geq 66$ years of age with Medicare health insurance between 2008 and 2017. After stratification by history of CVD, patients with a history of migraine were matched 1:4 to those without a history of migraine, based on calendar year, age, and sex. Patients were followed through December 31, 2017 for ischemic stroke and CHD events including myocardial infarction or coronary revascularization. All analyses were done separately for patients with and without a history of CVD.

Results: Among patients without a history of CVD $(n=109,950$ including $n=21,990$ with migraine and $n=87,960$ without migraine), 1789 had an ischemic stroke and 3552 had a CHD event. The adjusted hazard ratio (HR) among patients with versus without migraine was 1.20 (95\% confidence interval [95\%Cl], 1.07-1.35) for ischemic stroke and $1.02(95 \% \mathrm{Cl}, 0.93-1.11)$ for CHD events. Compared to patients without migraine, those with migraine who were taking an opioid medication had a higher risk for ischemic stroke (adjusted HR 1.43 [95\%Cl, 1.20-1.69]), while those taking a triptan had a lower risk for CHD events (adjusted HR 0.79 [95\% Cl, 0.67-0.93]). Among patients with a history of CVD ( $n=79,515$ including $n=15,903$ with migraine and $n=63,612$ without migraine), 2960 had an ischemic stroke and 7981 had a CHD event. The adjusted HRs (95\%Cl) for ischemic stroke and CHD events associated with migraine were $1.27(1.17-1.39)$ and 0.99 (0.93-1.05), respectively. Patients with migraine taking an opioid medication had a higher risk for ischemic stroke (adjusted HR 1.21 [95\% Cl, 1.07-1.36]), while those taking a triptan had a lower risk for CHD events (adjusted HR 0.83 [95\% Cl, 0.72-0.95]), each versus those without migraine.

Conclusions: Older adults with migraine are at increased risk for ischemic stroke. The risk for ischemic stroke among older adults with migraine may differ by migraine medication classes.

Keywords: Migraine, Myocardial infarction, Coronary revascularization, Ischemic stroke

\footnotetext{
* Correspondence: emckinley@uabmc.edu

'Department of Epidemiology, University of Alabama at Birmingham, 1665 University Blvd, RPHB 523B, Birmingham, AL 35233-0013, USA

Full list of author information is available at the end of the article
}

(c) The Author(s). 2021 Open Access This article is licensed under a Creative Commons Attribution 4.0 International License, which permits use, sharing, adaptation, distribution and reproduction in any medium or format, as long as you give appropriate credit to the original author(s) and the source, provide a link to the Creative Commons licence, and indicate if changes were made. The images or other third party material in this article are included in the article's Creative Commons licence, unless indicated otherwise in a credit line to the material. If material is not included in the article's Creative Commons licence and your intended use is not permitted by statutory regulation or exceeds the permitted use, you will need to obtain permission directly from the copyright holder. To view a copy of this licence, visit http://creativecommons.org/licenses/by/4.0/. The Creative Commons Public Domain Dedication waiver (http://creativecommons.org/publicdomain/zero/1.0/) applies to the data made available in this article, unless otherwise stated in a credit line to the data. 


\section{Introduction}

Studies of middle-aged adults have shown migraine to be associated with an increased risk for cardiovascular disease (CVD) events, including ischemic stroke and coronary heart disease (CHD) events [1]. The mechanisms linking migraine to CVD events are unclear, but have been speculated to include cortical spreading depression, hypercoagulation, endothelial dysfunction, shared genetic risk, vasospasm, or a higher prevalence of cardiovascular risk factors among patients with migraine [2, 3]. The risk for CVD events is higher among older versus middle-aged adults [4]. However, many risk factors for CVD events in middle-aged adults, including serum cholesterol and blood pressure, are not associated with increased CVD risk in older adults [5]. Little is known about the risk for CVD events associated with migraine in older adults $[1,6]$.

It has been suggested that certain classes of medications used to treat migraine, including triptans and ergotamines, are associated with an increased risk for CVD events [6, 7]. Also, specific migraine medications, including triptans, are contra-indicated for some patients with a history of CVD or high CVD risk [8, 9]. Few data are available on the risk for CVD events among older adults taking different classes of migraine medication [10]. A better understanding of the CVD risk associated with migraine and the use of migraine medications in older adults may advance knowledge of, and inform appropriate use of, migraine therapies in this population.

The primary objective of the current study was to compare the risk for ischemic stroke and CHD events among older US adults with versus without migraine. Since an association between some migraine medications and an increased risk for CVD events has been reported, we also analyzed the risk for ischemic stroke and CHD events among older adults with migraine taking different migraine medication classes [11-14]. As the risk for CVD events is higher among adults with versus without a history of CVD [15], all analyses were conducted for patients with and without a history of CVD, separately.

\section{Methods}

We conducted a retrospective cohort study using data from a $5 \%$ random sample of Medicare beneficiaries. Medicare is a government health insurance program for US adults aged 65 years and older, and adults younger than 65 years with end-stage renal disease or who are disabled. Medicare data were obtained from the Centers for Medicare and Medicaid Services (CMS) Chronic Condition Data Warehouse. The institutional review board at the University of Alabama at Birmingham approved the study and waived the requirement to obtain informed consent.

\section{Study population}

We identified Medicare beneficiaries with a history of migraine between January 1, 2008 and December 31, 2017, using inpatient and outpatient healthcare utilization claims for migraine and pharmacy fills for acute migraine medications as defined in Supplemental Table 1 . To provide adequate time to identify patient characteristics including the presence of comorbidities, we restricted the study population to Medicare beneficiaries who were living in the US and had continuous inpatient, outpatient, and pharmacy coverage for the 365 days prior to meeting the definition of history of migraine. As we were interested in studying history of migraine in older adults, we further restricted the study population to Medicare beneficiaries $\geq 66$ years of age on the date they met the definition of history of migraine which means they were $\geq 65$ years of age 365 days prior to meeting the definition of history of migraine (i.e., at the start of the look-back period). We required each beneficiary to be alive on the date they met the criteria for having a history of migraine. For each beneficiary, the earliest date they met all of the inclusion criteria described above was defined as their index date.

To serve as a control group, we identified beneficiaries who did not have a history of migraine, as defined above, using all available Medicare claims on or before December 31, 2017. For each beneficiary without a history of migraine, we randomly selected a day between January 1, 2008 and December 31, 2017 to serve as their index date. We applied identical inclusion/exclusion criteria for beneficiaries without a history of migraine as for those with a history of migraine. Specifically, we restricted the analysis to patients without a history of migraine who lived in the US and had continuous inpatient, outpatient, and pharmacy coverage for the 365 days before their index date. We further restricted the analysis to beneficiaries $\geq 66$ years of age who were alive on their index date. For patients with and without a history of CVD, separately, beneficiaries without a history of migraine were frequency matched to those with a history of migraine four to one based on the calendar year of their index date, age in years on their index date, and sex.

\section{Patient characteristics}

We used Medicare beneficiary and claims data between January 1, 2007 and each patient's index date to define characteristics (Supplemental Table 2). In addition to age on their index date, sex, and history of CVD, patient characteristics analyzed included race/ethnicity, receiving a low-income subsidy to pay for their health insurance, smoking status, history of diabetes, hypertension, chronic kidney disease (CKD), heart failure, dementia, depression, an anxiety disorder, insomnia, cancer, 
epilepsy, and hospitalization within the past year. Among beneficiaries with migraine, we further identified those with a history of migraine with aura. Beneficiaries who did not meet the definition for comorbidities listed above were assumed not to have those conditions. Arealevel income was defined by the median income level within the patient's zip code of residence according to data from the 2017 American Community Survey [16]. We also used Medicare pharmacy claims within 90 days prior to each patient's index date to identify the use of antihypertensive medication, glucose-lowering medication, statins, non-statin lipid-lowering medications, medications for insomnia, and, among women, hormone replacement therapy. A list of these medications is provided in Supplemental Table 3.

\section{Migraine medication use}

For patients with a history of migraine, we used Medicare pharmacy claims within 90 days prior to each patient's index date to identify use of acute migraine medications (i.e., triptans, ergotamine, nonsteroidal antiinflammatory drugs [NSAID], and opioids) and preventive migraine medications (i.e., select antiepileptic agents, select antihypertensive agents, select antidepressants, botulinum toxin, and other agents). A list of the medications in each of these classes is provided in Supplemental Table 4.

\section{Cardiovascular outcomes}

Patients were followed from their index date through December 31, 2017 for ischemic stroke events and CHD events (i.e., myocardial infarction hospitalization or coronary revascularization), separately, with censoring occurring if they lost Medicare fee-for-service inpatient or outpatient coverage or died. The definitions of ischemic stroke and CHD events are provided in Supplemental Table 5. As a secondary outcome, we analyzed the risk for CVD events, defined as the composite of an ischemic stroke or CHD event.

\section{Statistical analysis}

All statistical analyses described below were conducted among Medicare beneficiaries with and without a history of CVD, separately. We calculated summary statistics of patient characteristics for those with and without a history of migraine. We calculated the cumulative incidence and incidence rates of ischemic stroke, CHD and CVD events for patients with and without a history of migraine accounting for the competing risk of all-cause mortality as described by Fine and Gray [17]. We used Cox proportional hazard models with the Breslow method for tie handling to estimate hazard ratios (HR) and $95 \%$ confidence intervals (CI) for the risk of ischemic stroke, CHD events, and composite CVD events among patients with versus without a history of migraine. Four models with progressive adjustment for covariates were used. Model 1 was unadjusted. Model 2 included adjustment for age, sex, and race/ethnicity. Model 3 included adjustment for age, sex, race/ethnicity, low-income subsidy, area-level income, smoking status, diabetes, hypertension, CKD, heart failure, dementia, depression, insomnia, cancer, epilepsy, and hospitalization within the past year. Model 4 included adjustment for the variables in the third model and use of antihypertensive medication, glucose-lowering medication, statins, non-statin lipid-lowering therapy, medication for insomnia, and among women, hormone replacement therapy. As prior studies have shown an association between migraine with aura and increased risk of ischemic stroke $[18,19]$, we also estimated incidence rates and HRs for ischemic stroke associated with a history of migraine with and without aura, separately.

The calculation of rates and HRs for ischemic stroke, CHD events, and CVD events described above was repeated comparing patients with migraine but not taking migraine medications, those with migraine taking each migraine medication class and taking two or more migraine medication classes, each versus their counterparts without migraine. Few patients with migraine with and without a history of CVD were using ergotamines or botulinum toxin and the number of outcome events during follow-up in these subgroups was low. Therefore, we did not analyze the risk for outcome events among patients with migraine taking ergotamines or botulinum toxin. All analyses were conducted using SAS 9.4 (SAS Institute) with a two-sided level of statistical significance of 0.05 .

\section{Results}

Overall, 37,893 Medicare beneficiaries with a history of migraine met the inclusion criteria for the current study, including 21,990 without a history of CVD and 15,903 with a history of CVD (Fig. 1). The 21,990 patients with a history of migraine who did not have a history of CVD were matched to 87,960 patients without a history of migraine or CVD. Also, the 15,903 patients with a history of migraine who had a history of CVD were matched to 63,612 patients without a history of migraine with a history of CVD.

\section{Patients without a history of CVD}

Compared to their counterparts without a history of migraine, patients with a history of migraine were more likely to have depression, an anxiety disorder, and insomnia, and to have been hospitalized in the prior year (Table 1). Patients with a history of migraine were also more likely to take medications for insomnia and, among women, hormone replacement therapy. 


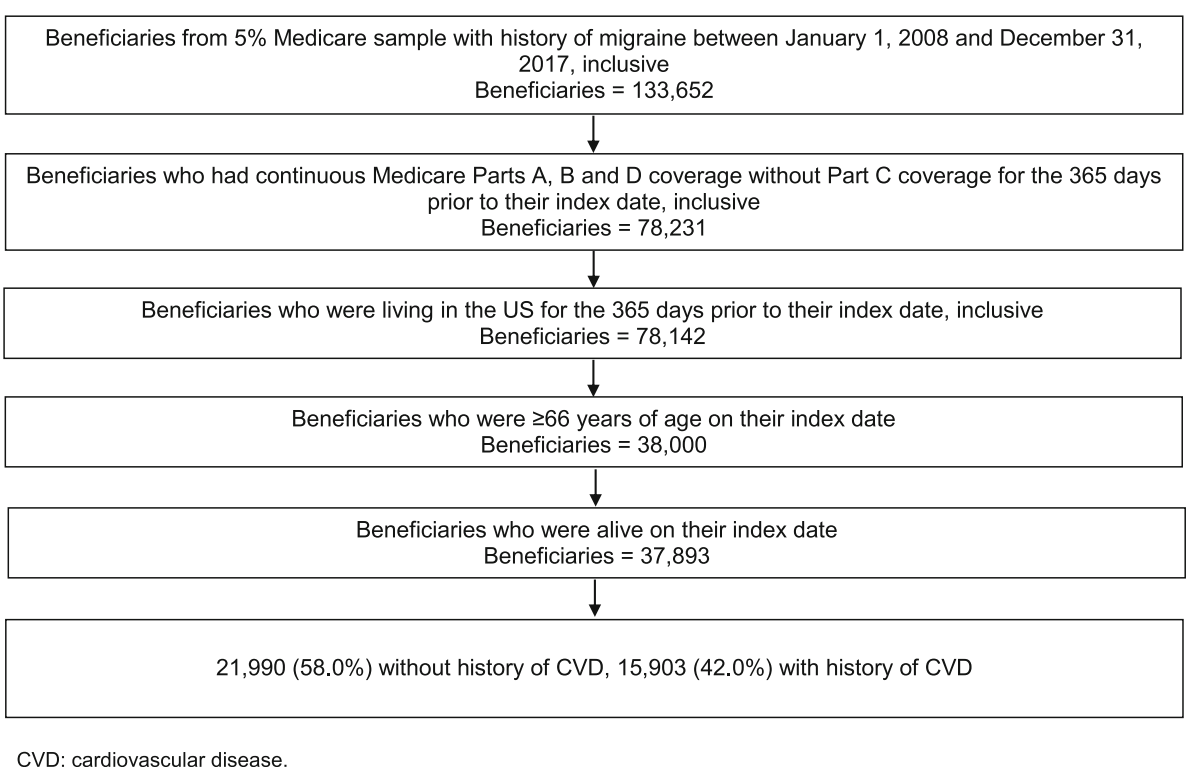

Fig. 1 Consort diagram of Medicare beneficiaries with a history of migraine included and not included in the current analysis. CVD: cardiovascular disease

Over a median follow-up time of 3.4 years (maximum of 10 years), among patients with and without a history of migraine, there were 406 and 1383 ischemic stroke events, respectively, 720 and 2832 CHD events, respectively, and 1084 and 4050 CVD events, respectively. The cumulative incidence of ischemic stroke was higher among patients with versus without a history of migraine (Fig. 2). There was no evidence of a difference in the cumulative incidence of CHD or CVD between patients with versus without a history of migraine. After multivariable adjustment, history of migraine was associated with a higher risk for ischemic stroke (HR 1.20 [95\% CI, 1.07-1.35]) and CVD events (HR 1.08 [95\% CI, 1.011.16]) but not CHD events (HR 1.02 [95\% CI, 0.931.11]) (Table 2). Compared to those without a history of migraine, the multivariable-adjusted $\mathrm{HR}$ for ischemic stroke events was 1.21 (95\% CI, 1.07-1.37) for patients with a history of migraine without aura and 1.18 (95\% CI, 0.88-1.57) for patients with a history of migraine with aura (Supplemental Table 6).

Among patients with a history of migraine, opioids and triptans were the acute migraine medications most commonly used, being taken by $36 \%$ of patients for both therapies, while antihypertensive medications were the most commonly used migraine-preventive therapy (Supplemental Table 7). After multivariable adjustment, patients with a history of migraine taking an opioid medication had a higher risk for ischemic stroke and CHD events versus their counterparts without a history of migraine. Patients with a history of migraine taking a triptan had a lower risk for CHD events versus those without a history of migraine, but there was no evidence of a difference in the risk for ischemic stroke.

\section{Patients with a history of CVD}

Among patients with a history of CVD, those who had a history of migraine were more likely to have depression, an anxiety disorder, and insomnia, and to have been hospitalized in the prior year compared to their counterparts without a history of migraine (Table 3). Patients with a history of migraine were also more likely to be taking medication for insomnia.

Over a median follow-up time of 3.1 years (maximum of 10 years), among patients with and without a history of migraine, there were 765 and 2195 ischemic stroke events, respectively, 1677 and 6304 CHD events, respectively and 2301 and 8062 CVD events, respectively. The cumulative incidence of ischemic stroke and CVD events but not CHD events was higher among patients with a history of migraine versus without a history of migraine (Fig. 3). After multivariable adjustment, a history of migraine was associated with a higher risk for ischemic stroke (HR 1.27 [95\% CI, 1.17-1.39]) and CVD events (HR 1.06 [95\% CI, 1.01-1.12]) but not for CHD events (HR 0.99 [95\% CI, 0.93-1.05]) (Table 4). After multivariable adjustment and compared to patients without a history of migraine, the HR for ischemic stroke events was 1.27 (95\% CI, 1.16-1.39) and 1.29 (95\% CI, 1.06-1.57) for patients with a history of migraine without and with aura, respectively (Supplemental Table 8 ).

Opioids (47\%) and antihypertensive medications (54\%) were the most commonly used acute and preventive 
Table 1 Characteristics of patients without a history of cardiovascular disease who had and did not have a history of migraine

\begin{tabular}{|c|c|c|}
\hline & \multicolumn{2}{|c|}{ History of Migraine } \\
\hline & $\begin{array}{l}\text { No } \\
(n=87,960)\end{array}$ & $\begin{array}{l}\text { Yes } \\
(n=21,990)\end{array}$ \\
\hline \multicolumn{3}{|c|}{ Calendar year of the index date, $\mathrm{N}(\%)$} \\
\hline 2008 & $9268(10.5)$ & $2317(10.5)$ \\
\hline 2009 & $5648(6.4)$ & $1412(6.4)$ \\
\hline 2010 & $5368(6.1)$ & $1342(6.1)$ \\
\hline 2011 & $6076(6.9)$ & $1519(6.9)$ \\
\hline 2012 & $6596(7.5)$ & $1649(7.5)$ \\
\hline 2013 & $8200(9.3)$ & $2050(9.3)$ \\
\hline 2014 & $10,744(12.2)$ & $2686(12.2)$ \\
\hline 2015 & $10,348(11.8)$ & $2587(11.8)$ \\
\hline 2016 & $12,164(13.8)$ & $3041(13.8)$ \\
\hline 2017 & $13,548(15.4)$ & $3387(15.4)$ \\
\hline \multicolumn{3}{|l|}{ Age, years, N (\%) } \\
\hline $66-70$ & $55,096(62.6)$ & $13,774(62.6)$ \\
\hline $71-75$ & $16,948(19.3)$ & $4237(19.3)$ \\
\hline $76-80$ & $8660(9.8)$ & $2165(9.8)$ \\
\hline $81-85$ & $4504(5.1)$ & $1126(5.1)$ \\
\hline$\geq 86$ & $2752(3.1)$ & $688(3.1)$ \\
\hline Age, years, mean (SD) & $71.3(5.6)$ & $70.8(5.8)$ \\
\hline Females, N (\%) & $74,616(84.8)$ & $18,654(84.8)$ \\
\hline \multicolumn{3}{|l|}{ Race/Ethnicity, N (\%) } \\
\hline Non-Hispanic Black & $6353(7.2)$ & $818(3.7)$ \\
\hline Non-Hispanic White & $75,573(85.9)$ & $20,030(91.1)$ \\
\hline Hispanic & $1435(1.6)$ & $317(1.4)$ \\
\hline Asian & $1750(2.0)$ & $211(1.0)$ \\
\hline Other & $2849(3.2)$ & $614(2.8)$ \\
\hline Low-income subsidy, N (\%) & $19,343(22.0)$ & 4135 (18.8) \\
\hline \multicolumn{3}{|l|}{ Area level median income, N (\%) } \\
\hline$<\$ 35,000$ & $6204(7.1)$ & $1193(5.4)$ \\
\hline$\$ 35,000-\$ 49,999$ & $26,285(29.9)$ & $5935(27.0)$ \\
\hline$\$ 50,000-\$ 74,999$ & $33,563(38.2)$ & $8476(38.5)$ \\
\hline$\geq \$ 75,000$ & $21,908(24.9)$ & $6386(29.0)$ \\
\hline Smoking, N (\%) & $6783(7.7)$ & $2669(12.1)$ \\
\hline Diabetes, N (\%) & $19,873(22.6)$ & $3780(17.2)$ \\
\hline Hypertension, N (\%) & $55,190(62.7)$ & $13,264(60.3)$ \\
\hline Chronic kidney disease, N (\%) & $11,009(12.5)$ & $3132(14.2)$ \\
\hline History of heart failure, N (\%) & $3240(3.7)$ & $825(3.8)$ \\
\hline Depression, N (\%) & $8783(10.0)$ & $4730(21.5)$ \\
\hline Anxiety disorders, N (\%) & $8008(9.1)$ & $4222(19.2)$ \\
\hline Insomnia, N (\%) & $3865(4.4)$ & $2141(9.7)$ \\
\hline History of dementia, N (\%) & $3776(4.3)$ & $999(4.5)$ \\
\hline Cancer, N (\%) & $13,191(15.0)$ & $4231(19.2)$ \\
\hline Epilepsy, N (\%) & $1669(1.9)$ & $993(4.5)$ \\
\hline
\end{tabular}


Table 1 Characteristics of patients without a history of cardiovascular disease who had and did not have a history of migraine (Continued)

\begin{tabular}{|c|c|c|}
\hline & \multicolumn{2}{|c|}{ History of Migraine } \\
\hline & $\begin{array}{l}\text { No } \\
(n=87,960)\end{array}$ & $\begin{array}{l}\text { Yes } \\
(n=21,990)\end{array}$ \\
\hline Hospitalization in the prior year, N (\%) & $8714(9.9)$ & $5323(24.2)$ \\
\hline \multicolumn{3}{|l|}{ Medication use, N (\%) } \\
\hline Antihypertensive medication & $48,837(55.5)$ & $11,887(54.1)$ \\
\hline Glucose-lowering medication & $11,987(13.6)$ & $2063(9.4)$ \\
\hline Statins & $29,473(33.5)$ & 7247 (33.0) \\
\hline Non-statin lipid-lowering medication & $2901(3.3)$ & $793(3.6)$ \\
\hline Medication for insomnia & $11,604(13.2)$ & 7039 (32.0) \\
\hline Hormone replacement therapy among women & $4473(6.0)$ & $2260(12.1)$ \\
\hline Migraine with aura, N (\%) & - & $2657(12.1)$ \\
\hline
\end{tabular}

$S D$ standard deviation

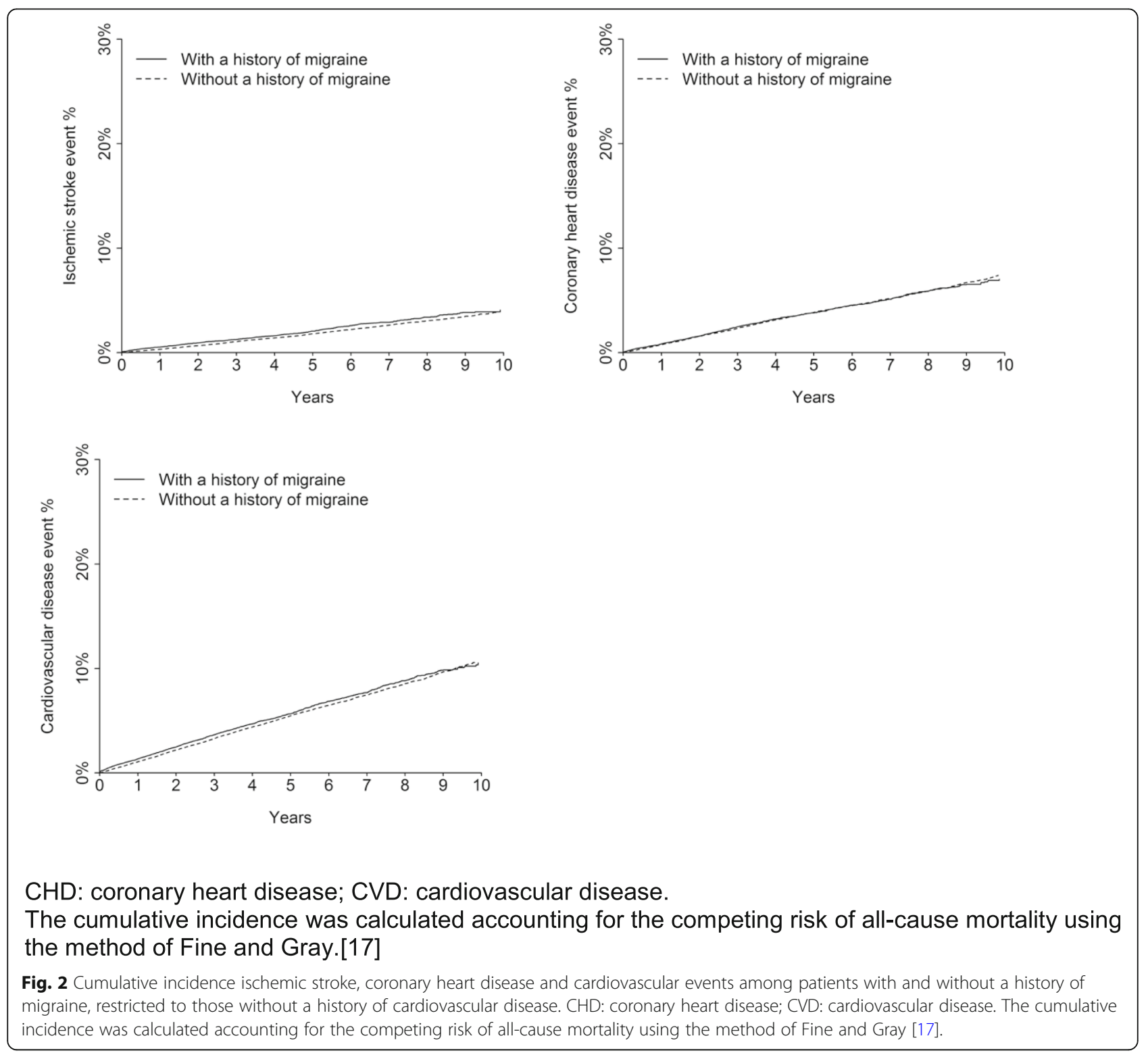


Table $\mathbf{2}$ Incidence rates and hazard ratios for ischemic stroke, coronary heart disease and cardiovascular disease events associated with a history of migraine among patients without a history of cardiovascular disease

\begin{tabular}{|c|c|c|}
\hline & \multicolumn{2}{|c|}{ History of migraine } \\
\hline & $\begin{array}{l}\text { No } \\
(n=87,960)\end{array}$ & $\begin{array}{l}\text { Yes } \\
(n=21,990)\end{array}$ \\
\hline \multicolumn{3}{|l|}{ Ischemic stroke } \\
\hline Number of events & 1383 & 406 \\
\hline Follow-up in person-years & 342,211 & 86,726 \\
\hline Incidence rate $(95 \% \mathrm{Cl})^{\mathrm{a}}$ & $4.0(3.8,4.3)$ & $4.7(4.2,5.1)$ \\
\hline \multicolumn{3}{|l|}{ Hazard ratio $(95 \% \mathrm{Cl})$} \\
\hline Model 1 & 1 (ref) & $1.16(1.03,1.29)$ \\
\hline Model 2 & 1 (ref) & $1.21(1.08,1.35)$ \\
\hline Model 3 & 1 (ref) & $1.21(1.08,1.36)$ \\
\hline Model 4 & 1 (ref) & $1.20(1.07,1.35)$ \\
\hline \multicolumn{3}{|l|}{ Coronary heart disease $^{b}$} \\
\hline Number of events & 2832 & 720 \\
\hline Follow-up in person-years & 338,452 & 85,866 \\
\hline Incidence rate $(95 \% \mathrm{Cl})^{\mathrm{a}}$ & $8.4(8.1,8.7)$ & $8.4(7.8,9.0)$ \\
\hline \multicolumn{3}{|l|}{ Hazard ratio $(95 \% \mathrm{Cl})$} \\
\hline Model 1 & 1 (ref) & $1.00(0.92,1.09)$ \\
\hline Model 2 & 1 (ref) & $1.01(0.93,1.09)$ \\
\hline Model 3 & 1 (ref) & $1.01(0.93,1.10)$ \\
\hline Model 4 & 1 (ref) & $1.02(0.93,1.11)$ \\
\hline \multicolumn{3}{|l|}{ Composite CVD events } \\
\hline Number of events & 4050 & 1084 \\
\hline Follow-up in person-years & 335,734 & 84,942 \\
\hline Incidence rate $(95 \% \mathrm{Cl})^{\mathrm{a}}$ & $12.1(11.7,12.4)$ & $12.8(12.0,13.5)$ \\
\hline \multicolumn{3}{|l|}{ Hazard ratio $(95 \% \mathrm{Cl})$} \\
\hline Model 1 & 1 (ref) & $1.06(0.99,1.13)$ \\
\hline Model 2 & 1 (ref) & $1.08(1.01,1.15)$ \\
\hline Model 3 & 1 (ref) & $1.08(1.01,1.16)$ \\
\hline Model 4 & 1 (ref) & $1.08(1.01,1.16)$ \\
\hline
\end{tabular}

${ }^{a}$ Rates are expressed per 1000 person-years

b Includes myocardial infarction or coronary revascularization

Model 1: Unadjusted model

Model 2: Adjusted for age, sex, and race/ethnicity

Model 3: Adjusted for variables in the second model and low income, arealevel income, smoking, diabetes, hypertension, CKD, history of heart failure, dementia, depression, insomnia, cancer, epilepsy, and hospitalization within the past year

Model 4: Adjusted for variables in Model 3 and use of antihypertensive medication, diabetes medication, barbiturates, benzodiazepines, antihistamine medication for insomnia, non-benzodiazepine medication for insomnia, sedative hypnotics, and sedative antidepressants, statins, non-statin lipidlowering therapy, and hormone replacement therapy

migraine medications among patients with a history of migraine, respectively (Supplemental Table 9). Also, 15\% of patients with a history of migraine were taking a triptan. After multivariable adjustment and compared to patients without a history of migraine, patients with a history of migraine who were taking an NSAID, opioid medication, antiepileptic agent, antihypertensive medication, antidepressant and two or more migraine agents had a higher risk for ischemic stroke. Patients with a history of migraine taking a triptan had a lower risk for CHD and CVD events versus those without a history of migraine.

\section{Discussion}

In the current analysis, the risk for ischemic stroke was higher among older adults with versus without a history of migraine. This association was present for patients with and without a history of CVD. Compared to patients without a history of migraine, the higher risk for ischemic stroke was present among patients with a history of migraine taking an opioid medication, but not among those taking a triptan. There was no evidence of a difference in the risk for CHD events for older adults with and without a history of migraine. However, patients with a history of migraine taking a triptan had lower risk for CHD events when compared to patients without migraine.

In previous studies of primarily middle-aged adults, migraine had been associated with an increased risk for stroke and CHD [1, 20-22]. In a meta-analysis of 16 cohort studies including more than one million participants, a history of migraine was associated with an increased risk for stroke (adjusted HR 1.41 [95\% CI, 1.25-1.61]) and myocardial infarction (adjusted HR 1.23 [95\% CI, 1.03-1.43]) [1]. However, substantial heterogeneity was present when comparing results across studies in this meta-analysis [1]. Few data are available examining the association of migraine with ischemic stroke and CHD events among older adults $[1,6]$. In a study including 1919 adults $\geq 65$ years of age, late-life non-migraine headache was associated with an increased risk for stroke [23]. There was no association between migraine and risk for stroke in this study. However, only 73 total stroke events, including two among those with migraine, occurred during follow up of this cohort. In another study that included 1292 adults (mean age $68 \pm$ 9 years), migraine was associated with increased risk of stroke among smokers (adjusted HR 3.17; 95\% CI 1.13, 8.85) but not in nonsmokers (adjusted HR 0.77; 95\% CI $0.44,1.35)$ [24]. In the current analysis, with a larger sample of older US adults with and without a history of migraine as well as thousands of stroke and CHD events that occurred during follow-up, a history of migraine was associated with a higher risk for ischemic stroke, but not with CHD events.

In a prior analysis of the Women's Health Study, women who had migraine with aura had a higher risk for ischemic stroke compared to women without migraine [18]. However, women who had migraine without 
Table 3 Characteristics of patients with a history of cardiovascular disease who had and did not have a history of migraine

\begin{tabular}{|c|c|c|}
\hline & \multicolumn{2}{|c|}{ History of Migraine } \\
\hline & $\begin{array}{l}\text { No } \\
(n=63,612)\end{array}$ & $\begin{array}{l}\text { Yes } \\
(n=15,903)\end{array}$ \\
\hline \multicolumn{3}{|c|}{ Calendar year of the index date, N (\%) } \\
\hline 2008 & $6860(10.8)$ & $1715(10.8)$ \\
\hline 2009 & $4560(7.2)$ & $1140(7.2)$ \\
\hline 2010 & $4668(7.3)$ & $1167(7.3)$ \\
\hline 2011 & $5620(8.8)$ & $1405(8.8)$ \\
\hline 2012 & $6032(9.5)$ & $1508(9.5)$ \\
\hline 2013 & $5972(9.4)$ & $1493(9.4)$ \\
\hline 2014 & $7276(11.4)$ & $1819(11.4)$ \\
\hline 2015 & $6652(10.5)$ & $1663(10.5)$ \\
\hline 2016 & $7708(12.1)$ & $1927(12.1)$ \\
\hline 2017 & $8264(13.0)$ & $2066(13.0)$ \\
\hline \multicolumn{3}{|l|}{ Age, years, N (\%) } \\
\hline $66-70$ & $21,352(33.6)$ & $5338(33.6)$ \\
\hline $71-75$ & $15,204(23.9)$ & $3801(23.9)$ \\
\hline $76-80$ & $12,096(19.0)$ & $3024(19.0)$ \\
\hline $81-85$ & $8456(13.3)$ & $2114(13.3)$ \\
\hline$\geq 86$ & $6504(10.2)$ & $1626(10.2)$ \\
\hline Age, years, mean (SD) & $75.4(7.3)$ & $75.1(7.2)$ \\
\hline Females, N (\%) & $48,904(76.9)$ & $12,226(76.9)$ \\
\hline \multicolumn{3}{|l|}{ Race/Ethnicity, N (\%) } \\
\hline Non-Hispanic Black & $6277(9.9)$ & $1105(6.9)$ \\
\hline Non-Hispanic White & $53,070(83.4)$ & $13,833(87.0)$ \\
\hline Hispanic & $1434(2.3)$ & $395(2.5)$ \\
\hline Asian & $1404(2.2)$ & $259(1.6)$ \\
\hline Other & $1427(2.2)$ & $311(2.0)$ \\
\hline Low-income subsidy, N (\%) & $23,437(36.8)$ & $6075(38.2)$ \\
\hline \multicolumn{3}{|l|}{ Area level median income, N (\%) } \\
\hline$<\$ 35,000$ & $6396(10.1)$ & $1508(9.5)$ \\
\hline$\$ 35,000-\$ 49,999$ & 21,397 (33.6) & $5240(32.9)$ \\
\hline$\$ 50,000-\$ 74,999$ & $23,010(36.2)$ & $5659(35.6)$ \\
\hline$\geq \$ 75,000$ & $12,809(20.1)$ & $3496(22.0)$ \\
\hline Smoking, N (\%) & $9446(14.8)$ & $3648(22.9)$ \\
\hline Diabetes, N (\%) & $28,424(44.7)$ & $6455(40.6)$ \\
\hline Hypertension, N (\%) & $58,817(92.5)$ & $14,740(92.7)$ \\
\hline Chronic kidney disease, N (\%) & $22,642(35.6)$ & $6180(38.9)$ \\
\hline History of heart failure, N (\%) & $19,115(30.0)$ & $4871(30.6)$ \\
\hline Depression, N (\%) & $10,197(16.0)$ & $4633(29.1)$ \\
\hline Anxiety disorders, N (\%) & $8682(13.6)$ & $4273(26.9)$ \\
\hline Insomnia, N (\%) & $3832(6.0)$ & $1823(11.5)$ \\
\hline History of dementia, N (\%) & $9243(14.5)$ & $2519(15.8)$ \\
\hline Cancer, N (\%) & $11,064(17.4)$ & 3429 (21.6) \\
\hline Epilepsy, N (\%) & 3547 (5.6) & $1896(11.9)$ \\
\hline
\end{tabular}


Table 3 Characteristics of patients with a history of cardiovascular disease who had and did not have a history of migraine (Continued)

\begin{tabular}{|c|c|c|}
\hline & \multicolumn{2}{|c|}{ History of Migraine } \\
\hline & $\begin{array}{l}\text { No } \\
(n=63,612)\end{array}$ & $\begin{array}{l}\text { Yes } \\
(n=15,903)\end{array}$ \\
\hline Hospitalization in the prior year, N (\%) & $18,033(28.3)$ & $8119(51.1)$ \\
\hline \multicolumn{3}{|l|}{ Medication use, N (\%) } \\
\hline Antihypertensive medication & $51,432(80.9)$ & $12,587(79.1)$ \\
\hline Glucose-lowering medication & $15,089(23.7)$ & 3009 (18.9) \\
\hline Statins & $34,512(54.3)$ & $8230(51.8)$ \\
\hline Non-statin lipid-lowering medication & $3830(6.0)$ & $987(6.2)$ \\
\hline Medication for insomnia & $12,014(18.9)$ & $5576(35.1)$ \\
\hline Hormone replacement therapy among women & $1918(3.0)$ & $834(6.8)$ \\
\hline Migraine with aura, N (\%) & - & $2245(14.1)$ \\
\hline
\end{tabular}

$S D$ standard deviation

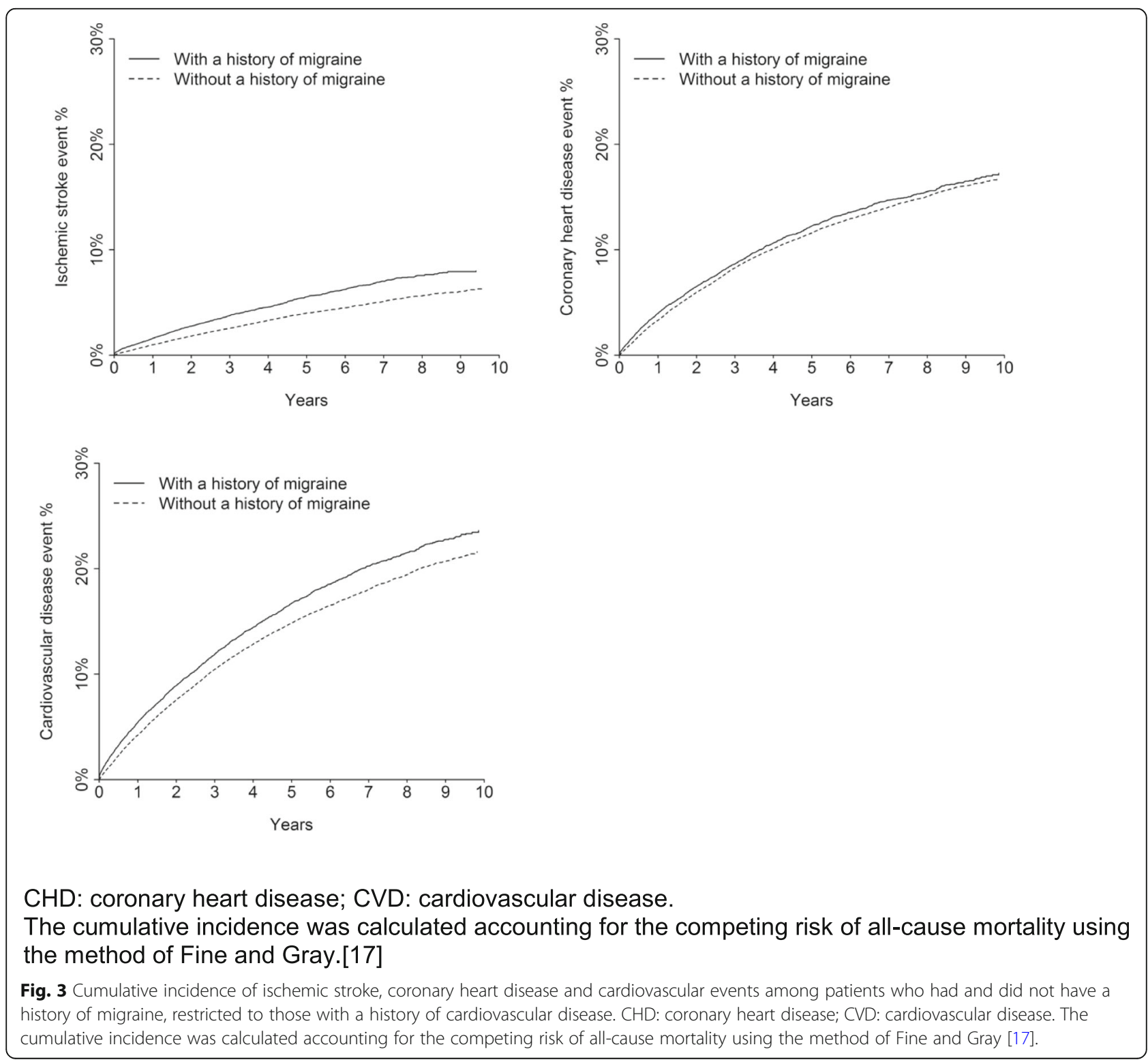


Table 4 Incidence rates and hazard ratios for ischemic stroke, coronary heart disease and cardiovascular disease events associated with a history of migraine among patients with a history of cardiovascular disease

\begin{tabular}{|c|c|c|}
\hline & \multicolumn{2}{|c|}{ History of migraine } \\
\hline & $\begin{array}{l}\text { No } \\
(n=63,612)\end{array}$ & $\begin{array}{l}\text { Yes } \\
(n=15,903)\end{array}$ \\
\hline \multicolumn{3}{|l|}{ Ischemic stroke } \\
\hline Number of events & 2195 & 765 \\
\hline Follow-up in person-years & 227,257 & 58,097 \\
\hline Incidence rate $(95 \% \mathrm{Cl})^{\mathrm{a}}$ & $9.7(9.3,10.1)$ & $13.2(12.2,14.1)$ \\
\hline \multicolumn{3}{|l|}{ Hazard ratio $(95 \% \mathrm{Cl})$} \\
\hline Model 1 & 1 (ref) & $1.37(1.26,1.48)$ \\
\hline Model 2 & 1 (ref) & $1.39(1.28,1.51)$ \\
\hline Model 3 & 1 (ref) & $1.25(1.15,1.36)$ \\
\hline Model 4 & 1 (ref) & $1.27(1.17,1.39)$ \\
\hline \multicolumn{3}{|l|}{ Coronary heart disease $^{b}$} \\
\hline Number of events & 6304 & 1677 \\
\hline Follow-up in person-years & 217,059 & 55,859 \\
\hline Incidence rate $(95 \% \mathrm{Cl})^{\mathrm{a}}$ & $29.0(28.3,29.8)$ & $30.0(28.6,31.5)$ \\
\hline \multicolumn{3}{|l|}{ Hazard ratio $(95 \% \mathrm{Cl})$} \\
\hline Model 1 & 1 (ref) & $1.04(0.99,1.10)$ \\
\hline Model 2 & 1 (ref) & $1.04(0.98,1.09)$ \\
\hline Model 3 & 1 (ref) & $0.99(0.93,1.04)$ \\
\hline Model 4 & 1 (ref) & $0.99(0.93,1.05)$ \\
\hline \multicolumn{3}{|l|}{ Composite CVD events } \\
\hline Number of events & 8062 & 2301 \\
\hline Follow-up in person-years & 213,557 & 54,347 \\
\hline Incidence rate $(95 \% \mathrm{Cl})^{\mathrm{a}}$ & $37.8(36.9,38.6)$ & $42.3(40.6,44.1)$ \\
\hline \multicolumn{3}{|l|}{ Hazard ratio (95\% Cl) } \\
\hline Model 1 & 1 (ref) & $1.13(1.08,1.18)$ \\
\hline Model 2 & 1 (ref) & $1.13(1.08,1.18)$ \\
\hline Model 3 & 1 (ref) & $1.06(1.01,1.11)$ \\
\hline Model 4 & 1 (ref) & $1.06(1.01,1.12)$ \\
\hline
\end{tabular}

${ }^{a}$ Rates are expressed per 1000 person-years

b Includes myocardial infarction or coronary revascularization

Model 1: Unadjusted model

Model 2: Adjusted for age, sex, and race/ethnicity

Model 3: Adjusted for variables in the second model and low income, area-

level income, smoking, diabetes, hypertension, chronic kidney disease, history

of heart failure, dementia, depression, insomnia, cancer, epilepsy, and

hospitalization within the past year

Model 4: Adjusted for variables in Model 3 and use of antihypertensive medication, diabetes medication, barbiturates, benzodiazepines, antihistamine medication for insomnia, non-benzodiazepine medication for insomnia, sedative hypnotics, and sedative antidepressants, statins, non-statin lipidlowering therapy, and hormone replacement therapy

aura did not have an increased risk for ischemic stroke compared to those without migraine. The incidence rate of ischemic stroke in the current study was higher for individuals with a history of migraine, with and without aura, compared to those without a history of migraine.
However, the current results need to be interpreted with caution as some patients with migraine with aura may have been misclassified as without aura if they did not have a specific diagnosis code for this condition.

Triptans are contraindicated for patients with a history of coronary artery disease, cerebrovascular disease or peripheral vascular disease, or with uncontrolled hypertension [8]. Consistent with prior studies, the use of triptans was lower among patients with a history of migraine included in the current analysis who had versus those who did not have a history of CVD $[25,26]$. The use of triptans by patients with migraine was associated with a lower risk for CHD events compared to those without a history of migraine. This finding may be explained by physicians selectively prescribing triptans to those patients with a history of migraine perceived to be at a lower risk for future CVD events.

The use of opioids is not recommended by any migraine treatment guideline [27-30]. However, prior studies have shown that the use of opioids is high among middle-aged adults with migraine [31, 32]. In the current study, opioids were the acute migraine medications most commonly used by older adults with a history of migraine, both among those without and with a history of CVD. The use of opioids has been associated with an increased risk of CVD events [12-14]. This association may be mediated by opioid receptors in the cardiovascular system [33]. For example, it has been suggested that chronic use of opioid may increase the risk for ischemic stroke through an altered expression of tight junction proteins which could result in a disruption in the blood brain barrier [34]. In a study of Medicare beneficiaries from New Jersey and Pennsylvania, opioid use was associated with more than twice the risk of myocardial infarction compared with the use of NSAIDs [13]. Among patients with a history of CVD in the current study, those with history of migraine taking opioids had a higher risk of ischemic stroke and CHD events versus their counterparts without a history of migraine. However, we cannot rule out confounding by indication. This would occur, for example, if patients at high risk for $\mathrm{CHD}$ events were more likely to be treated with opioids versus other migraine medications.

In addition to the efficacy of a therapy, comorbid and coexisting conditions, potential adverse events, and patient preferences should be taken into consideration when developing a treatment plan for individuals with a history of migraine [28]. For many older individuals with a history of migraine, cardiovascular contraindications to migraine-specific therapies can pose substantial treatment challenges. Current treatment guidelines for episodic migraine do not provide specific recommendations for the management of older adults or those with increased CVD risk [27-30]. More specific 
recommendations for the treatment of older adults with migraine, particularly those with a history of CVD or high CVD risk, may lead to better migraine management by reducing the frequency, duration, and severity of migraine attacks and subsequently improving quality of life in this population.

The current study has several strengths. We included a large sample of adults $\geq 65$ years with and without migraine. Since most older US adults have health insurance through Medicare, the current findings have a high degree of generalizability to older adults in the US [35]. Additionally, data on stroke, CHD, and CVD outcomes were available over 10 years of follow-up. We used a number of strategies to control for possible confounding and bias. We used the same inclusion/exclusion criteria and algorithms to identify outcome events among patients with and without migraine. We also used a matched design to control for differences in age, sex, and history of CVD. Lastly, we included numerous covariates in the statistical models to control potential residual confounding. However, the current study has several limitations. Patients with a history of migraine were identified using diagnosis codes and pharmacy claims data which may not capture individuals who are undiagnosed or who do not seek medical care for migraine. The current results may have been attenuated if patients with migraine were misclassified as not having migraine and still had CVD events. We were unable to assess time since migraine diagnosis, and attack frequency and severity for patient's migraine attacks because these metrics are unavailable in claims data. We were unable to evaluate non-prescription treatment for alleviating migraine pain including over the counter medications, massage, hot or cold compresses, and nutraceuticals. Pharmacy claims can only identify that beneficiaries filled a prescription, but not that they actually took the medication. Additionally, many of these medications are taken as needed and we do not know how frequently patients used them. Finally, the preventive migraine medications and some acute migraine medications (e.g., opioids) included in this study have indications for other diseases. It is possible that patients with a history of migraine were taking these medications to treat other conditions.

\section{Conclusion}

In the current study of Medicare beneficiaries, rates of ischemic stroke were higher among those with versus without migraine, but migraine was not associated with a higher risk for CHD events. The risk for ischemic stroke among patients with migraine differed by migraine medication classes. The current findings have implications for clinicians treating older individuals with migraine. These results suggest the need for more specific clinical guidelines and recommendations to appropriately treat older adults with migraine.

\section{Abbreviations \\ CHD: Coronary heart disease; Cl: Confidence intervals; CKD: Chronic kidney disease; CMS: Centers for Medicare and Medicaid Services; \\ CVD: Cardiovascular disease; HR: Hazard ratios; NSAID: Nonsteroidal anti- inflammatory drug}

\section{Supplementary Information}

The online version contains supplementary material available at https:/doi. org/10.1186/s10194-021-01338-z.

\begin{abstract}
Additional file 1: Table S1. Definition of a history of migraine. Table S2. Definition of patient characteristics. Table S3. Antihypertensive medications, glucose lowering medications, statins, non-statin lipidlowering medication, medications for insomnia and hormone replacement therapy. Table S4. Migraine medications. Table S5. Definitions of ischemic stroke and coronary heart disease events. Table S6. Incidence rates and hazard ratios for ischemic stroke associated with a history of migraine with and without aura among patients without a history of cardiovascular disease. Table S7. Incidence rates and hazard ratios for ischemic stroke, coronary heart disease and cardiovascular disease associated with a history of migraine and migraine medication drug classes among patients without a history of cardiovascular disease. Table S8. Incidence rates and hazard ratios for risk of ischemic stroke associated with a history of migraine without and with aura among patients with a history of cardiovascular disease. Table S9. Incidence rates and hazard ratios for ischemic stroke, coronary heart disease and cardiovascular disease associated with a history of migraine and migraine medications among patients with a history of cardiovascular disease.
\end{abstract}

\section{Authors' contributions}

ECM contributed to the interpretation of the results and manuscript content. CLL contributed to the study concept, study design, interpretation of results, and manuscript content. RSR contributed to the study concept, study design interpretation of results, and manuscript content. LC conducted the data analysis. VC contributed to the study concept, study design, interpretation of results, and manuscript content. LDC contributed to the study concept, study design, interpretation of results, and manuscript content. PM contributed to the study concept, study design, interpretation of results, and manuscript content. RU contributed to the study concept, study design, developed the final report, and manuscript content. MEF contributed to the study concept, study design, interpretation of results, and manuscript content. The author(s) read and approved the final manuscript.

\section{Funding}

The design and conduct of the study, interpretation of the results, and preparation of the manuscript was supported through a research grant from Amgen, Inc. (Thousand Oaks, CA). The academic authors conducted all analyses and maintained the rights to publish this article.

\section{Availability of data and materials}

The datasets generated and/or analyzed during the current study will be made available from the corresponding author upon reasonable request.

\section{Declarations}

Ethics approval and consent to participate

The institutional review board at the University of Alabama at Birmingham approved the study and waived the requirement to obtain informed consent.

Consent for publication

Not applicable

Competing interests

ECM receives research support from Amgen, Inc. 
CLL receives research support from Amgen, Inc., Aralez, Eli Lilly; honoraria from Abbvie/Allergan; serves on the advisory board for Novartis.

RSR receives research support from Amgen, Inc., Astra Zeneca, Novartis and Regeneron; consulting fees from Amgen, Inc., Amryt, C5, CVS Caremark, Novartis, Regeneron and 89 Bio; honoraria from Amgen, Inc., Kowa and Regeneron; royalties from Wolters Kluwer (UpToDate, Inc.); and has stock in MediMergent, LLC

VC is an employee and shareholder in Amgen, Inc.

$L D C$ receives research support from Amgen, Inc.

PM receives research support and consulting fees from Amgen, Inc.

$\mathrm{RU}$ is an employee and shareholder in Amgen, Inc.

MEF receives research support from Amgen, Inc., Novo Nordisk, and Novartis.

\section{Author details}

'Department of Epidemiology, University of Alabama at Birmingham, 1665 University Blvd, RPHB 523B, Birmingham, AL 35233-0013, USA. ${ }^{2}$ Centre for Headache, University of Toronto, Toronto, ON, Canada. ${ }^{3}$ Icahn School of Medicine at Mount Sinai, New York, NY, USA. ${ }^{4}$ Amgen Inc, Thousand Oaks, CA, USA. ${ }^{5}$ Peter Munk Cardiac Centre and Heart and Stroke Richard Lewar Centre, University of Toronto, Toronto, Canada.

\section{Received: 26 July 2021 Accepted: 1 October 2021}

Published online: 13 October 2021

\section{References}

1. Mahmoud AN, Mentias A, Elgendy AY, Qazi A, Barakat AF, Saad M, Mohsen A, Abuzaid A, Mansoor H, Mojadidi MK, Elgendy IY (2018) Migraine and the risk of cardiovascular and cerebrovascular events: a meta-analysis of 16 cohort studies including 1152407 subjects. BMJ Open 8(3):e020498. https://doi.org/10.1136/bmjopen-2017-020498

2. Bigal ME, Kurth T, Hu H, Santanello N, Lipton RB (2009) Migraine and cardiovascular disease: possible mechanisms of interaction. Neurology 72(21):1864-1871. https://doi.org/10.1212/WNL.0b013e3181a71220

3. Agostoni EC, Longoni M (2018) Migraine and cerebrovascular disease: still a dangerous connection? Neurol Sci 39(S1):S33-S37. https://doi.org/10.1007/ s10072-018-3429-8

4. Dhingra R, Vasan RS (2012) Age as a risk factor. Med Clin North Am 96(1): 87-91. https://doi.org/10.1016/j.mcna.2011.11.003

5. Ahmadi S-F, Streja E, Zahmatkesh G, Streja D, Kashyap M, Moradi H, Molnar MZ, Reddy U, Amin AN, Kovesdy CP, Kalantar-Zadeh K (2015) Reverse epidemiology of traditional cardiovascular risk factors in the geriatric population. J Am Med Dir Assoc 16(11):933-939. https://doi.org/10.1016/j.ja mda.2015.07.014

6. Roberto G, Raschi E, Piccinni C, Conti V, Vignatelli L, D'Alessandro R, de Ponti F, Poluzzi E (2015) Adverse cardiovascular events associated with triptans and ergotamines for treatment of migraine: systematic review of observational studies. Cephalalgia 35(2):118-131. https://doi.org/10.1177/ 0333102414550416

7. Albieri V, Olsen TS, Andersen KK (2016) Risk of stroke in Migraineurs using Triptans. Associations with age, sex, stroke severity and subtype. EBioMedicine 6:199-205 https://doi.org/10.1016/j.ebiom.2016.02.039

8. Ferrari MD, Roon KI, Lipton RB, Goadsby PJ (2001) Oral triptans (serotonin 5HT 1B/1D agonists) in acute migraine treatment: a meta-analysis of 53 trials. Lancet 358(9294):1668-1675. https://doi.org/10.1016/S0140-6736(01)06711-3

9. Dodick DW, Shewale AS, Lipton RB, Baum SJ, Marcus SC, Silberstein SD, Pavlovic JM, Bennett NL, Young WB, Viswanathan HN, Doshi JA, Weintraub H (2020) Migraine patients with cardiovascular disease and contraindications: an analysis of real-world claims data. J Prim Care Community Health 11:. https://doi.org/10.1177/2150132720963680: 215013272096368

10. Li H, Vincent M, Zhang $X$, Dennehy EB, Goodloe R, Aurora SK, Smith TR (2020) Acute migraine prescription patterns vary by baseline cardiovascular risk and clinical characteristics: a real-world evidence study. Pain Ther 9(2): 499-509. https://doi.org/10.1007/s40122-020-00167-3

11. Welch K, Mathew N, Stone P, Rosamond W, Saiers J, Gutterman D (2000) Tolerability of sumatriptan: clinical trials and post-marketing experience. Cephalalgia 20(8):687-695. https://doi.org/10.1111/j.1468-2982.2000.00116.x

12. Khodneva Y, Muntner P, Kertesz S, Kissela B, Safford MM (2015) Prescription opioid use and risk of coronary heart disease, stroke, and cardiovascular death among adults from a prospective cohort (REGARDS study). Pain Med 17:444-455 https://doi.org/10.1111/pme.12916
13. Solomon DH (2010) The comparative safety of analgesics in older adults with arthritis. Arch Intern Med 170(22):1968-1976. https://doi.org/10.1001/a rchinternmed.2010.391

14. Li L, Setoguchi S, Cabral H, Jick S (2013) Opioid use for noncancer pain and risk of myocardial infarction amongst adults. J Intern Med 273(5):511-526. https://doi.org/10.1111/joim.12035

15. D’Agostino RB, Russell MW, Huse DM et al (2000) Primary and subsequent coronary risk appraisal: new results from the Framingham study. Am Heart J 139(2):272-281. https://doi.org/10.1067/mhj.2000.96469

16. US Census Bureau American Community Survey (ACS). https://www.census. gov/programs-surveys/acs. Accessed 13 Apr 2020

17. Fine JP, Gray RJ (1999) A proportional hazards model for the subdistribution of a competing risk. J Am Stat Assoc 94(446):496-509. https://doi.org/10.1 080/01621459.1999.10474144

18. Kurth T, Gaziano JM, Cook NR, Logroscino G, Diener HC, Buring JE (2006) Migraine and risk of cardiovascular disease in women. JAMA 296(3):283-292. https://doi.org/10.1001/jama.296.3.283

19. Lee SY, Lim JS, Oh DJ, Kong IG, Choi HG (2019) Risk of ischaemic stroke in patients with migraine: a longitudinal follow-up study using a national sample cohort in South Korea. BMJ Open 9(4):1-8. https://doi.org/10.1136/ bmjopen-2018-027701

20. Buse DC, Reed ML, Fanning KM, Kurth T, Lipton RB (2017) Cardiovascular events, conditions, and procedures among people with episodic migraine in the US population: results from the American Migraine Prevalence and Prevention (AMPP) study. Headache J Head Face Pain 57(1):31-44. https:// doi.org/10.1111/head.12962

21. Becker C, Brobert GP, Almqvist PM, Johansson S, Jick SS, Meier CR (2007) Migraine and the risk of stroke, TIA, or death in the UK (CME). Headache J Head Face Pain 47(10):1374-1384. https://doi.org/10.1111/j.1526-4610.2007. 00937.x

22. Sacco S, Ornello R, Ripa P, Tiseo C, Degan D, Pistoia F, Carolei A (2015) Migraine and risk of ischaemic heart disease: a systematic review and metaanalysis of observational studies. Eur J Neurol 22(6):1001-1011. https://doi. org/10.1111/ene.12701

23. Norton J, Portet F, Gabelle A, Debette S, Ritchie K, Touchon J, Berr C (2016) Are migraine and non-migrainous headache risk factors for stroke in the elderly? Findings from a 12-year cohort follow-up. Eur J Neurol 23(9):14631470. https://doi.org/10.1111/ene.13060

24. Monteith TS, Gardener H, Rundek T, Elkind MSV, Sacco RL (2015) Migraine and risk of stroke in older adults. Neurology 85(8):715-721. https://doi.org/1 0.1212/WNL.0000000000001854

25. Bigal ME, Golden W, Buse D, Chen YT, Lipton RB (2010) Triptan use as a function of cardiovascular risk. A population-based study. Headache J Head Face Pain 50(2):256-263. https://doi.org/10.1111/j.1526-4610.2009.01595.x

26. Hall GC, Brown MM, Mo J, MacRae KD (2004) Triptans in migraine: the risks of stroke, cardiovascular disease, and death in practice. Neurology 62(4): 563-568. https://doi.org/10.1212/01.WNL.0000110312.36809.7F. https://doi. org/10.1212/01.WNL.0000110312.36809.7F

27. Holland S, Silberstein SD, Freitag F, Dodick DW, Argoff C, Ashman E, Quality Standards Subcommittee of the American Academy of Neurology and the American Headache Society (2012) Evidence-based guideline update: NSAI Ds and other complementary treatments for episodic migraine prevention in adults report of the quality standards subcommittee of the american academy of neurology and the American headache society. Neurology 78(17):1346-1353. https://doi.org/10.1212/WNL.0b013e3182535d0c

28. Marmura MJ, Silberstein SD, Schwedt TJ (2015) The acute treatment of migraine in adults: the american headache society evidence assessment of migraine pharmacotherapies. Headache 55(1):3-20. https://doi.org/10.1111/ head. 12499

29. Worthington I, Pringsheim T, Gawel MJ et al (2013) Canadian headache society guideline: acute drug therapy for migraine headache. Can J Neurol Sci 40(S2):S1-S80. https://doi.org/10.1017/s0317167100015109

30. Silberstein SD, Holland S, Freitag F, Dodick DW, Argoff C, Ashman E, Quality Standards Subcommittee of the American Academy of Neurology and the American Headache Society (2012) Evidence-based guideline update: pharmacologic treatment for episodic migraine prevention in adults: report of the Quality Standards Subcommittee of the American Academy of Neurology and the American Headache Society. Neurology 78(17):13371345. https://doi.org/10.1212/WNL.0b013e3182535d20

31. Buse DC, Pearlman SH, Reed ML, Serrano D, Ng-Mak DS, Lipton RB (2012) Opioid use and dependence among persons with migraine: results of the 
AMPP study. Headache 52(1):18-36. https://doi.org/10.1111/j.1526-4610.2 011.02050.x

32. Bonafede M, Wilson K, Xue F (2019) Long-term treatment patterns of prophylactic and acute migraine medications and incidence of opioidrelated adverse events in patients with migraine. Cephalalgia 39(9):10861098. https://doi.org/10.1177/0333102419835465

33. Feng Y, He X, Yang Y, Chao D, H. Lazarus L, Xia Y (2012) Current research on opioid receptor function. Curr Drug Targets 13(2):230-246. https://doi.org/1 $0.2174 / 138945012799201612$

34. Peyravian N, Dikici E, Deo S, Toborek M, Daunert S (2019) Opioid antagonists as potential therapeutics for ischemic stroke. Prog Neurobiol 182:101679 https://doi.org/10.1016/J.PNEUROBIO.2019.101679

35. Administration on Aging, Administration for Community Living, US Department of Health and Human Services (2018) A profile of older Americans: 2017

\section{Publisher's Note}

Springer Nature remains neutral with regard to jurisdictional claims in published maps and institutional affiliations.

Ready to submit your research? Choose BMC and benefit from:

- fast, convenient online submission

- thorough peer review by experienced researchers in your field

- rapid publication on acceptance

- support for research data, including large and complex data types

- gold Open Access which fosters wider collaboration and increased citations

- maximum visibility for your research: over $100 \mathrm{M}$ website views per year

At BMC, research is always in progress.

Learn more biomedcentral.com/submissions 